\title{
NECESSARY AND SUFFICIENT CONDITIONS FOR A DIFFERENCE CONSTITUTED BY FOUR DERIVATIVES OF A FUNCTION INVOLVING TRIGAMMA FUNCTION TO BE COMPLETELY MONOTONIC
}

\author{
FENG QI
}

\begin{abstract}
In the paper, by virtue of convolution theorem for the Laplace transforms, Bernstein's theorem for completely monotonic functions, and other techniques, the author finds necessary and sufficient conditions for a difference constituted by four derivatives of a function involving trigamma function to be completely monotonic.
\end{abstract}

Mathematics subject classification (2020): Primary 33B15; Secondary 26A48, 26A51, 26D07, 44A10. Keywords and phrases: Complete monotonicity, necessary and sufficient condition, difference, derivative, trigamma function, convolution theorem for the Laplace transforms, Bernstein's theorem for completely monotonic functions.

\section{REFERENCES}

[1] M. Abramowitz And I. A. Stegun (Eds), Handbook of Mathematical Functions with Formulas, Graphs, and Mathematical Tables, National Bureau of Standards, Applied Mathematics Series 55, Reprint of the 1972 edition, Dover Publications, Inc., New York, 1992.

[2] C. Berg, E. MASSA, AND A. P. Peron, A family of entire functions connecting the Bessel function $J_{1}$ and the Lambert $W$ function, Constr. Approx. 53 (2021), no. 1, 121-154; https://doi.org/10.1007/s00365-020-09499-x.

[3] Y.-M. ChU AND X.-H. Zhang, Necessary and sufficient conditions such that extended mean values are Schur-convex or Schur-concave, J. Math. Kyoto Univ. 48 (2008), no. 1, 229-238; https://doi.org/10.1215/kjm/1250280982.

[4] M. E. H. ISMAIL, Inequalities for gamma and q-gamma functions of complex arguments, Anal. Appl. (Singap.) 15 (2017), no. 5, 641-651; https ://doi . org/10.1142/S0219530516500093.

[5] M. E. H. ISMAIL AND M. E. MULDOON, Higher monotonicity properties of $q$-gamma and $q$-psi functions, Adv. Dyn. Syst. Appl. 8 (2013), no. 2, 247-259.

[6] A. W. Marshall, I. Olkin, And B. C. ARnold, Inequalities: Theory of Majorization and its Applications, 2nd Ed., Springer Verlag, New York/Dordrecht/Heidelberg/London, 2011; http://dx.doi.org/10.1007/978-0-387-68276-1.

[7] D. S. Mitrinović, J. E. PeČArić, And A. M. FinK, Classical and New Inequalities in Analysis, Kluwer Academic Publishers, Dordrecht-Boston-London, 1993; https://doi.org/10.1007/978-94-017-1043-5.

[8] F. QI, Complete monotonicity of a difference constituted by four derivatives of a function involving trigamma function, MDPI Preprints 2020, 2020110343, 9 pages; https://doi.org/10.20944/preprints202011.0343.v1.

[9] F. QI, Necessary and sufficient conditions for a difference defined by four derivatives of a function containing trigamma function to be completely monotonic, Appl. Comput. Math. 21 (2022), in press; available online at https://doi.org/10.31219/osf.io/56c2s.

[10] F. QI, Completely monotonic degree of a function involving trigamma and tetragamma functions, AIMS Math. 5 (2020), no. 4, 3391-3407; https://doi.org/10.3934/math. 2020219.

[11] F. QI, Decreasing monotonicity of two ratios defined by three or four polygamma functions, HAL (2020), available online at https://hal.archives-ouvertes.fr/hal-02998414. 
[12] F. QI, Lower bound of sectional curvature of Fisher-Rao manifold of beta distributions and complete monotonicity of functions involving polygamma functions, Results Math. 77 (2022), in press; https://doi.org/10.20944/preprints202011.0315.v1.

[13] F. QI, Decreasing property and complete monotonicity of two functions constituted via three derivatives of a function involving trigamma function, Math. Slovaca 71 (2021), in press; available online at https://doi.org/10.31219/osf .io/whb2q.

[14] F. QI, Necessary and sufficient conditions for a ratio involving trigamma and tetragamma functions to be monotonic, Turkish J. Inequal. 5 (2021), no. 1, 50-59.

[15] F. QI, Necessary and sufficient conditions for complete monotonicity and monotonicity of two functions defined by two derivatives of a function involving trigamma function, Appl. Anal. Discrete Math. 15 (2021), no. 1, in press; available online at https://doi.org/10.2298/AADM191111014Q.

[16] F. QI, Necessary and sufficient conditions for two functions defined by two derivatives of a function involving trigamma function to be completely monotonic, TWMS J. Pure Appl. Math. 13 (2022), no. 1, in press.

[17] F. QI, Some properties of several functions involving polygamma functions and originating from the sectional curvature of the beta manifold, São Paulo J. Math. Sci. 14 (2020), no. 2, 614-630; https://doi.org/10.1007/s40863-020-00193-1.

[18] F. QI AND B.-N. GUO, From inequalities involving exponential functions and sums to logarithmically complete monotonicity of ratios of gamma functions, J. Math. Anal. Appl. 493 (2021), no. 1, Article 124478, 19 pages; https://doi.org/10.1016/j.jmaa.2020.124478.

[19] F. QI, L.-X. HAN, AND H.-P. Y IN, Monotonicity and complete monotonicity of two functions defined by three derivatives of a function involving trigamma function, Miskolc Math. Notes 23 (2022), in press; available online at https://hal.archives-ouvertes.fr/hal-02998203.

[20] F. QI, D.-W. NiU, D. Lim, AND B.-N. GUO, Some logarithmically completely monotonic functions and inequalities for multinomial coefficients and multivariate beta functions, Appl. Anal. Discrete Math. 14 (2020), no. 2, 512-527; https : //doi .org/10.2298/AADM191111033Q.

[21] F. QI, X.-T. ShI, M. MAhmoud, AND F.-F. LIU, Schur-convexity of the Catalan-Qi function related to the Catalan numbers, Tbilisi Math. J. 9 (2016), no. 2, 141-150; http://dx.doi.org/10.1515/tmj-2016-0026.

[22] R. L. Schilling, R. SOng, And Z. VondraČEK, Bernstein Functions, 2nd ed., de Gruyter Studies in Mathematics 37, Walter de Gruyter, Berlin, Germany, 2012; https://doi.org/10.1515/9783110269338.

[23] H.-N. SHI, Two Schur-convex functions related to Hadamard-type integral inequalities, Publ. Math. Debrecen 78 (2011), no. 2, 393-403; https : //doi .org/10.5486/PMD . 2011.4777.

[24] D. V. WidDER, The Laplace Transform, Princeton University Press, Princeton, 1946.

[25] Y. W U, F. QI, AND H.-N. SHI, Schur-harmonic convexity for differences of some special means in two variables, J. Math. Inequal. 8 (2014), no. 2, 321-330; http://dx.doi.org/10.7153/jmi-08-23.

[26] A.-M. XU AND Z.-D. CEN, Qi's conjectures on completely monotonic degrees of remainders of asymptotic formulas of di- and tri-gamma functions, J. Inequal. Appl. 2020, Paper No. 83, 10 pages; https://doi.org/10.1186/s13660-020-02345-5.

[27] Z.-H. YANG, J.-F. TIAN, AND M.-H. HA, A new asymptotic expansion of a ratio of two gamma functions and complete monotonicity for its remainder, Proc. Amer. Math. Soc. 148 (2020), no. 5, 2163-2178; https://doi .org/10.1090/proc/14917.

[28] H.-P. Yin, X.-M. LiU, J.-Y. WANG, AND B.-N. GUO, Necessary and sufficient conditions on the Schur convexity of a bivariate mean, AIMS Math. 6 (2021), no. 1, 296-303; https://doi.org/10.3934/math.2021018.

[29] H.-P. YIN, H.-N. SHI, AND F. QI, On Schur m-power convexity for ratios of some means, J. Math. Inequal. 9 (2015), no. 1, 145-153; https://doi.org/10.7153/jmi-09-14. 